DOI 10.5216/ia.v45i3.65002

\title{
CARACTERÍSTICAS DO PARFOR: UMA REVISÃO DE DISSERTAÇÕES E TESES BRASILEIRAS
}

\author{
JuCENILTON AlVES dOS SANTOS \\ Rosa Maria MORAES AnUnCIATO \\ Universidade Federal de São Carlos (UFSCar), São Carlos, São Paulo, Brasil
}

\begin{abstract}
Resumo: A partir de levantamento realizado no Catálogo de Teses e Dissertações da Coordenação de Aperfeiçoamento de Pessoal de Nível Superior (CAPES), com o objetivo de analisar as características do Programa Nacional de Formação de Professores (PARFOR), busca-se colaborar com o avanço de ações e políticas voltadas para a formação em serviço de professores da educação básica. Trata-se de pesquisa bibliográfica, utilizando os operadores booleanos com os descritores PARFOR AND Pedagogia OR Anos Iniciais OR Educação Infantil. Os resultados alcançados confirmam que o PARFOR estabelece relações com as categorias identificadas, ampliando as possibilidades de certificação de professores no cenário nacional, além de contribuir para análise de práticas pedagógicas. As implicações nas práticas podem se constituir em campo de estudos futuros. Palavras-chave: PARFOR. Políticas Públicas. Formação de Professores. Pedagogia.
\end{abstract}

INTRODUÇÃO

A pesquisa está fundamentada em bases teóricas relacionadas à formação de professores e em normativas/legislações publicadas em órgãos oficiais do governo federal, como a CAPES e o Instituto Nacional de Estudos e Pesquisas Educacionais Anísio Teixeira (INEP). Este trabalho tem o intuito de analisar as características do Programa Nacional de Formação de Professores (PARFOR) em teses e dissertações brasileiras. Foram selecionados trabalhos acerca da educação infantil e dos anos iniciais do ensino fundamental.

O PARFOR é uma ação destinada a professores em efetivo exercício, com fins de atender a demanda da formação inicial e continuada dos professores das redes públicas de educação básica. Para Gatti (2014), a Política Nacional de Formação de Profissionais do Magistério da Educação Básica, ao privilegiar a ação de formação em serviço, deixa lacunas importantes na política de formação docente.

\footnotetext{
Conta-se, em nível nacional, não com uma política geral relativa à formação de professores, mas com uma política parcial orientada para a formação em serviço de quadros não suficientemente titulados nas redes educacionais. A Política Nacional de Formação de Profissionais do Magistério de Educação Básica (BRASIL, 2009) dirige-se apenas à formação de profissionais já em serviço e à
} 
formação continuada, deixando intocadas questões de fundo quanto à formação inicial de professores (GATTI, 2014).

Considerando a perspectiva de Gatti (2014), com relação ao PARFOR como política voltada apenas à formação de profissionais já em serviço e à formação continuada, entendemos que esse programa oferece, em rede nacional, cursos de licenciatura para professores que estão em exercício. Nessa direção, Gatti explica que isso se configura como formação continuada por ser realizada "em serviço", ou seja:

Seria uma formação complementar dos professores em exercício propiciando-lhes a titulação adequada a seu cargo, que deveria ser dada nos cursos regulares, mas que lhe é oferecida como um complemento de sua formação, uma vez que já está trabalhando na rede (GATTI, 2008).

O PARFOR está em 510 municípios brasileiros, com 3.043 turmas implantadas de 2009 a 2019, segundo dados oficiais obtidos no site da CAPES sobre os números (https://www.capes.gov.br/educacao-basica/parfor). Foram matriculados 100.408, sendo que 53.512 professores já foram formados em 104 instituições participantes (BRASIL, 2020).

Nesse cenário, buscamos responder às questões que norteiam essa revisão bibliográfica: quais contextos, temáticas e objetivos de pesquisa têm levado pesquisadores a investigarem o PARFOR como política pública educacional? Quais características do PARFOR têm sido discutidas nas pesquisas brasileiras?

\section{CAMINHOS METODOLÓGICOS}

A revisão de literatura é bastante usada no meio acadêmico no qual o pesquisador busca informações e dados de outros pesquisadores em publicações como livros, artigos, teses e dissertações de origem nacional ou internacional e em bancos de dados na internet. Noronha e Ferreira definem as pesquisas de revisão de literatura como:

estudos que analisam a produção bibliográfica em determinada área temática, dentro de um recorte de tempo, fornecendo uma visão geral ou um relatório do estado-da-arte sobre um tópico específico, evidenciando novas ideias, métodos, subtemas que têm recebido maior ou menor ênfase na literatura selecionada (NORONHA; FERREIRA, 2000, p. 191).

Esse tipo de pesquisa exerce, portanto, um papel muito importante na propagação da informação, pois é um tipo de estudo que reúne e discute informações produzidas em uma determinada área de estudo, sendo, em nosso caso, a formação de professores. Com finalidades científicas e acadêmicas, sugere-se consulta às bases de dados bibliográficos, por possuírem informações de melhor qualidade, a exemplo do Catálogo de Teses e Dissertações da CAPES, utilizado nesta pesquisa, pois, sabendo qual 
temática será abordada, é necessário definir qual fonte de informação será empregada (CUNHA, 2001).

Para realizarmos esse levantamento bibliográfico, fizemos um mapeamento no Catálogo de Teses e Dissertações da CAPES, que compreende o ano de 2012, quando surgiram os primeiros trabalhos, até janeiro de 2020. Esse período corresponde aos anos em que as pesquisas foram armazenadas na plataforma. Ao consultar o catálogo da CAPES, utilizamos, inicialmente, o descritor "PARFOR" em caixa-alta. Disso, constatamos que, em dezembro de 2019, havia 177 títulos de teses e dissertações armazenados no sistema com esse descritor. Esse número oscilou para 190 pesquisas em janeiro de 2020.

Levando em consideração a necessidade de uma melhor compilação das pesquisas armazenadas na plataforma, utilizamos o Modelo booleano que, segundo Baeza-Yates \& Ribeiro-Neto (1999, apud SOUZA, 2006), "é baseado na teoria dos conjuntos, sendo simples e elegante". Por meio dele, o usuário pode utilizar os operadores booleanos OR, AND e NOT para estabelecer relações específicas de ocorrência com as palavras-chave, de forma a especificar os documentos a serem recuperados. O resultado de uma busca utilizando esses operadores é composto por uma série de documentos cuja representação satisfaz às restrições lógicas da expressão de busca. Utilizando esse método, fizemos uma busca no catálogo usando as expressões "PARFOR OR parfor" que gerou um resultado de 190 pesquisas, ou seja, não houve mudança no total, concluindo que não há alteração do uso de maiúscula ou minúscula na sigla.

Para delimitar esse resultado, atendendo ao nosso interesse de pesquisa, analisamos os títulos, resumos e palavras-chave das 190 pesquisas resultantes da busca inicial, pois consideramos que não poderíamos descartar as pesquisas sem analisá-las em sua totalidade. Para isso, buscamos os seguintes descritores: "Pedagogia", "Anos Iniciais", "Educação Infantil" e "Formação em Serviço", que, em algumas pesquisas, alguns autores utilizam termos afins: "Formação de Professores" e "Formação Continuada". As pesquisas que possuíam como uma das temáticas centrais no corpo do texto os descritores mencionados foram consideradas para este estudo. Feito isso, identificamos, das 190 pesquisas, apenas 22 (vinte e duas) no escopo da temática.

Os trabalhos em que esses descritores não estavam presentes no título, no resumo e nas palavras-chave foram descartados, além dos que se referiam a programas de pós-graduação não relacionados com a grande área Educação, a exemplo de Ciências da Computação, Ciências da Motricidade, Ciências da Saúde, Ciências Sociais Aplicadas, Multidisciplinar, Ciências Exatas e da Terra, Serviço Social, Teologia, Administração Pública, entre outros, exceto aqueles em que constavam os descritores "Pedagogia", "Anos Iniciais", "Educação Infantil" e "Formação em Serviço" ou "Formação de Professores" ou "Formação Continuada".

Para a organização dos dados e resultados, apresentamos um quadro sintético com o mapeamento das 22 pesquisas, considerando a área de concentração, o tipo de pesquisa e a instituição/autor/ano. Fizemos também uma descrição geral e um breve balanço de todas as 22 pesquisas delimitadas para identificar as principais temáticas abordadas e os objetivos relacionados ao PARFOR. A partir da análise das temáticas, sentimos necessidade de ler os trabalhos completos e identificar os que possuem mais relação com os conceitos que pretendemos investigar. 
Logo após, apresentamos o foco, ou seja, a centralidade das pesquisas de acordo com os descritores utilizados: "Pedagogia", "Anos Iniciais", "Educação Infantil" e "Formação em Serviço" ou "Formação de Professores" ou "Formação Continuada". Em seguida, após leitura dos 22 (vinte e dois) trabalhos, identificamos os conceitos teóricos que têm sido utilizados no trato do PARFOR como políticas públicas na área de formação de professores pelos pesquisadores: Políticas Públicas e PARFOR; Formação em Serviço ou Formação Continuada ou Formação de Professores; Profissionalização Docente; Desenvolvimento Profissional; Reflexão; Identidade Docente. No escopo deste artigo, daremos ênfase ao conceito de Políticas Públicas e PARFOR. Por fim, nas considerações finais, apresentamos um panorama das pesquisas analisadas através de uma breve análise reflexiva sobre os avanços e lacunas acerca da temática central.

\section{ORGANIZAÇÃO DOS DADOS E DISCUSSÃO}

Para nos situarmos em relação à delimitação das pesquisas mapeadas, e para conhecermos melhor o material encontrado, apresentamos o quadro 01 a seguir, com a área de concentração, tipo de pesquisa (dissertação ou tese) e instituição/autor/ano das 22 , sendo 15 dissertações e 07 teses.

Quadro 01: Revisão de Teses e dissertações

\begin{tabular}{|c|c|c|}
\hline $\begin{array}{c}\text { Área de Concentração } \\
\text { Educação }\end{array}$ & Tipo de Pesquisa & $\begin{array}{c}\text { Instituição da pesquisa/ } \\
\text { Autor/Ano }\end{array}$ \\
\hline Educação & Dissertação & PUC-CAMPINAS - SANTOS (2013) \\
\hline Educação & Dissertação & UFPA - TEIXEIRA (2018) \\
\hline $\begin{array}{c}\text { Família na Sociedade } \\
\text { Contemporânea }\end{array}$ & Dissertação & UFPA - FREIRES (2017) \\
\hline Educação & Tese & UCSAL - AMORIM (2013) \\
\hline Ensino de Ciências e Matemática & Dissertação & UNISANTOS - SALGADO (2013) \\
\hline Ensino & Dissertação & UFS - SOUZA (2015) \\
\hline Educação & Dissertação & FUVATES - PEIXOTO (2015) \\
\hline Educação & Dissertação & UNISANTOS - CARVALHO (2014) \\
\hline Educação e Diversidade & Dissertação & UFMA - PEREIRA (2016) \\
\hline Língua e Cultura & UNEB - SACRAMENTO DE SOUSA \\
\hline Educação & Dissertação & UNISANTOS - VERNI (2016) \\
\hline Educação & Tese & UFPA - OLIVEIRA (2014) \\
\hline Educação & Dissertação & UFPA - PIRES (2017) \\
\hline Educação & Tese & UFSCar - SANTOS (2017) \\
\hline Educação e Ensino & Dissertação & UECE - RODRIGUES (2017) \\
\hline Educação & Tese & UNESP - ZANLORENZI (2019) \\
\hline Básica & Dissertação & UFPA - SILVA (2019) \\
\hline Educação & Tese & UFBA - GONÇALVES (2013) \\
\hline Educação & Tese & UFBA - PAIM (2013) \\
\hline
\end{tabular}


SANTOS, J. A. dos; ANUNCIATO, R. M. M.

\begin{tabular}{|c|c|c|}
\hline Educação & Dissertação & UFBA - PORTELA (2019) \\
\hline Educação & Dissertação & UESB - CARDOSO (2018) \\
\hline
\end{tabular}

Fonte: Dados da pesquisa. Elaborado pelos autores (2020).

Para realizarmos o mapeamento e obtermos uma visão geral da pesquisa acadêmica brasileira, quando relacionada ao PARFOR, foram adotados como material de análise as 22 pesquisas filtradas pelos descritores "Pedagogia", "Anos Iniciais", "Educação Infantil" e "Formação em Serviço" ou "Formação de Professores" ou "Formação Continuada". Sete pesquisas foram produzidas no estado da Bahia, seis no estado de São Paulo, cinco no estado do Pará, uma no estado do Ceará, uma em Sergipe, uma no Rio Grande do Sul e uma no Maranhão.

Como podemos observar, as pesquisas são predominantemente da Área de Concentração em Educação, sendo 12 dissertações e cinco teses no total de 22 pesquisas, e as demais são de áreas afins e/ou correlatas: Currículo e Gestão da Educação Básica; Família na Sociedade Contemporânea; Língua e Cultura; Ensino; Ensino de Ciências e Matemática.

Os propósitos/objetivos das pesquisas (trabalhos de teses e dissertações) dos autores mencionados no quadro 01 foram diversos. Para ilustrar de uma maneira mais explícita, possibilitando-nos uma visão mais geral, compusemos o quadro 02, que demonstra a temática e o objetivo central de cada trabalho e seu referido autor de forma sistematizada, considerando os descritores escolhidos.

\begin{tabular}{|c|c|c|}
\multicolumn{2}{|c}{ Quadro 02 - Demonstrativo das teses e dissertações: temática e objetivo } \\
\hline PESQUISADOR/ANO & TEMATICA & OBJETIVO \\
\hline Santos (2013) & $\begin{array}{c}\text { Processo de } \\
\text { (re)significação da } \\
\text { profissão a partir da } \\
\text { formação em exercício. }\end{array}$ & $\begin{array}{c}\text { Identificar quais as (re)significações da } \\
\text { profissão são elaboradas pelas } \\
\text { professoras de Educação Infantil a partir } \\
\text { do processo de formação em exercício. }\end{array}$ \\
\hline Teixeira (2018) & $\begin{array}{c}\text { Revisão de literatura sobre } \\
\text { o PARFOR. }\end{array}$ & $\begin{array}{c}\text { Analisar a produção acadêmica e } \\
\text { científica sobre o PARFOR em periódicos } \\
\text { nacionais no período de 2013 a 2018. }\end{array}$ \\
\hline Freires (2017) & $\begin{array}{c}\text { Formação em serviço no } \\
\text { PARFOR e prática } \\
\text { pedagógica. }\end{array}$ & $\begin{array}{c}\text { Analisar as contribuições do PARFOR } \\
\text { para a prática pedagógica dos } \\
\text { professores-alunos do curso de } \\
\text { Pedagogia/UFPA. }\end{array}$ \\
\hline Amorim (2013) & $\begin{array}{c}\text { Demandas das dimensões } \\
\text { do público e do privado na } \\
\text { formação. }\end{array}$ & $\begin{array}{c}\text { Analisar como os posicionamentos do } \\
\text { "eu" dialogam e se movem ao longo do } \\
\text { processo formativo oferecido pelo } \\
\text { PARFOR. }\end{array}$ \\
\hline Salgado (2013) & $\begin{array}{c}\text { A formação de professoras- } \\
\text { estudantes e o ensino de } \\
\text { Música. }\end{array}$ & $\begin{array}{c}\text { Refletir sobre as percepções e/ou } \\
\text { representações sociais das professoras- } \\
\text { estudantes da Pedagogia/PARFOR sobre } \\
\text { o ensino de Música. }\end{array}$ \\
\hline
\end{tabular}




\begin{tabular}{|c|c|c|}
\hline Souza (2015) & $\begin{array}{l}\text { A formação inicial em } \\
\text { serviço do professor. }\end{array}$ & $\begin{array}{c}\text { Investigar a formação em serviço do } \\
\text { PARFOR/UNEB, polo Cristópolis-BA, a } \\
\text { partir da percepção dos/das } \\
\text { professores-alunos/professoras-alunas } \\
\text { que atuam na disciplina Matemática na } \\
\text { Educação Básica. }\end{array}$ \\
\hline Peixoto (2015) & $\begin{array}{l}\text { Práticas pedagógicas de } \\
\text { professores da educação } \\
\text { infantil. }\end{array}$ & $\begin{array}{c}\text { Investigar quais as contribuições do } \\
\text { curso de Pedagogia PARFOR - IFRS-BG } \\
\text { para a melhoria das práticas } \\
\text { pedagógicas de professores que atuam } \\
\text { na Educação Infantil. }\end{array}$ \\
\hline Carvalho (2014) & $\begin{array}{c}\text { Necessidades e } \\
\text { expectativas de } \\
\text { professoras-estudantes, } \\
\text { sobre a prática profissional }\end{array}$ & $\begin{array}{l}\text { Compreender as } \\
\text { necessidades/expectativas das } \\
\text { professoras-estudantes da } \\
\text { Pedagogia/PARFOR sobre o contexto de } \\
\text { formação docente frente aos desafios da } \\
\text { prática profissional. }\end{array}$ \\
\hline Pereira (2016) & $\begin{array}{l}\text { Prática pedagógica e } \\
\text { percepção dos alunos- } \\
\text { professores sobre a } \\
\text { formação dada pelo } \\
\text { PARFOR. }\end{array}$ & $\begin{array}{l}\text { Analisar as implicações do curso de } \\
\text { Licenciatura em Pedagogia/PARFOR na } \\
\text { prática pedagógica dos alunos- } \\
\text { professores, focalizando a percepção } \\
\text { que estes têm sobre a formação e se } \\
\text { essa formação os encaminhou para uma } \\
\text { prática pedagógica diferente. }\end{array}$ \\
\hline $\begin{array}{c}\text { Sacramento de Sousa } \\
(2016)\end{array}$ & $\begin{array}{l}\text { Formação em exercício e } \\
\text { desenvolvimento das } \\
\text { práticas pedagógicas }\end{array}$ & $\begin{array}{l}\text { Identificar as contribuições do Programa } \\
\text { PARFOR/UNEB para a (re)construção das } \\
\text { práticas docentes dos seus egressos. }\end{array}$ \\
\hline Rosa (2017) & $\begin{array}{l}\text { Interculturalidade na } \\
\text { Formação de Professores } \\
\text { de língua estrangeira }\end{array}$ & $\begin{array}{l}\text { Verificar como a perspectiva } \\
\text { intercultural foi configurada e quais são } \\
\text { as implicações na prática dos egressos } \\
\text { do curso LEMI/PARFOR/UESC. }\end{array}$ \\
\hline Verni (2016) & $\begin{array}{l}\text { Qualidade da educação } \\
\text { infantil. }\end{array}$ & $\begin{array}{l}\text { Contribuir com estudos sobre as } \\
\text { possibilidades de consolidação de } \\
\text { política de formação nas escolas, } \\
\text { enfocando a compreensão de } \\
\text { professores-egressos e demais } \\
\text { professores e gestores das mesmas } \\
\text { unidades escolares a respeito de } \\
\text { qualidade na educação infantil. }\end{array}$ \\
\hline Oliveira (2014) & $\begin{array}{l}\text { Ensino de Ciências Naturais } \\
\text { e concepções e práticas } \\
\text { pedagógicas dos docentes } \\
\text { em formação. }\end{array}$ & $\begin{array}{l}\text { Compreender o Ensino de Ciências } \\
\text { Naturais em escolas públicas da região } \\
\text { metropolitana de Belém, a partir das } \\
\text { concepções e das Práticas pedagógicas } \\
\text { dos docentes em formação pelo } \\
\text { PARFOR que atuam nos anos Iniciais do } \\
\text { Ensino Fundamental. }\end{array}$ \\
\hline
\end{tabular}


SANTOS, J. A. dos; ANUNCIATO, R. M. M.

\begin{tabular}{|c|c|c|}
\hline Pires (2017) & $\begin{array}{l}\text { Profissionalização e } \\
\text { mudanças na prática } \\
\text { pedagógica. }\end{array}$ & $\begin{array}{l}\text { Identificar e analisar quais as } \\
\text { contribuições do curso de } \\
\text { Pedagogia/PARFOR para a mudança das } \\
\text { práticas pedagógicas das professoras de } \\
\text { Igarapé-Miri. }\end{array}$ \\
\hline Santos (2017) & Professores-alunos. & $\begin{array}{l}\text { Estudar a relação professor-aluno } \\
\text { quando os alunos já são professores. }\end{array}$ \\
\hline Rodrigues (2017) & $\begin{array}{c}\text { Formação no PARFOR e } \\
\text { implicações na prática } \\
\text { docente. }\end{array}$ & $\begin{array}{l}\text { Analisar os significados atribuídos pelos } \\
\text { egressos do PARFOR - Pedagogia à } \\
\text { formação adquirida por estes neste } \\
\text { curso, observando através da percepção } \\
\text { dos mesmos as repercussões desta } \\
\text { formação para a sua prática docente. }\end{array}$ \\
\hline Zanlorenzi (2019) & $\begin{array}{l}\text { Influências do PARFOR na } \\
\text { formação profissional. }\end{array}$ & $\begin{array}{l}\text { Analisar o Curso em Pedagogia Primeira } \\
\text { Licenciatura (PARFOR) como um } \\
\text { Programa Federal e como um Curso de } \\
\text { Formação inicial de Professores } \\
\text { oferecido pela UEM aos professores em } \\
\text { exercício na escola pública da Educação } \\
\text { Básica. }\end{array}$ \\
\hline Silva (2019) & $\begin{array}{l}\text { Culturas na Escrita de } \\
\text { Graduandos do PARFOR- } \\
\text { LETRAS. }\end{array}$ & $\begin{array}{l}\text { Investigar como as culturas acadêmica, } \\
\text { escolar e local se materializam em } \\
\text { discurso na escrita sobre as práticas de } \\
\text { ensino de LP de alunos-professores do } \\
\text { PARFOR Letras da UFPA em uma turma } \\
\text { de São Sebastião da Boa Vista, no } \\
\text { Marajó. }\end{array}$ \\
\hline Gonçalves (2013) & $\begin{array}{l}\text { Entrecurrículo, experiência } \\
\text { e metaformação e } \\
\text { hermenêutica no campo } \\
\text { da formação. }\end{array}$ & $\begin{array}{l}\text { Compreender o processo formativo } \\
\text { vivido por um grupo de professores da } \\
\text { Educação Básica, tomando como ponto } \\
\text { de partida o espaço ocupado por suas } \\
\text { experiências. }\end{array}$ \\
\hline Paim (2013) & $\begin{array}{l}\text { Formação de professores } \\
\text { em atuação em Física. }\end{array}$ & $\begin{array}{l}\text { Compreender as re-existências } \\
\text { epistemológicas e formativas de } \\
\text { professores-estudantes aos atos de } \\
\text { currículo constitutivos do Curso de } \\
\text { Licenciatura em Física do PARFOR. }\end{array}$ \\
\hline Portela (2019) & $\begin{array}{l}\text { A formação no PARFOR a } \\
\text { partir das narrativas de } \\
\text { professoras egressas. }\end{array}$ & $\begin{array}{l}\text { Compreender a percepção de } \\
\text { professoras sobre a formação docente, a } \\
\text { partir de uma política pública } \\
\text { educacional situada, o PARFOR, por } \\
\text { entender sua especificidade em formar } \\
\text { docentes que atuam na rede pública da } \\
\text { educação básica. }\end{array}$ \\
\hline Cardoso (2018) & $\begin{array}{l}\text { Educação do campo e } \\
\text { prática pedagógica. }\end{array}$ & $\begin{array}{l}\text { Analisar os impactos do PARFOR como } \\
\text { política de formação inicial na prática } \\
\text { pedagógica dos Egressos do Curso de } \\
\text { Pedagogia do PARFOR/UESB, que atuam } \\
\text { em espaços campesinos de Vitória da } \\
\text { Conquista, obedecendo ao recorte } \\
\text { temporal de 2012-2015. }\end{array}$ \\
\hline
\end{tabular}

Fonte: Brasil/MEC/Capes (2012-2020). Elaborado pelos autores (2020). 
No quadro 02, fizemos uma descrição geral e um breve balanço para identificar as principais temáticas abordadas e seus objetivos relacionados ao PARFOR e aos descritores outrora mencionados, assim como a demanda de estudo.

No que diz respeito ao foco das pesquisas relacionadas ao PARFOR, nos 22 trabalhos selecionados, os resultados encontrados em relação aos descritores escolhidos foram:

a) Pedagogia (SANTOS, 2013; TEIXEIRA, 2018; FREIRES, 2017; AMORIM, 2013; SALGADO, 2013; PEIXOTO, 2015; CARVALHO, 2014; PEREIRA, 2016; SACRAMENTO DE SOUSA, 2016; VERNI, 2016; OLIVEIRA, 2014; PIRES, 2017; SANTOS, 2017; RODRIGUES, 2017; ZANLORENZI, 2019; PORTELA, 2019; CARDOSO, 2018).

b) Anos Iniciais (OLIVEIRA, 2014).

c) Educação Infantil (SANTOS, 2013; PEIXOTO, 2015; VERNI, 2016).

d) Formação em Serviço ou Formação de Professores ou Formação Continuada (CARDOSO, 2018; PEIXOTO, 2015; PIRES, 2017; PORTELA, 2019; SANTOS, 2013; TEIXEIRA, 2018; FREIRES, 2017; AMORIM, 2013; SALGADO, 2013; SOUZA, 2015; CARVALHO, 2014; PEREIRA, 2016; SACRAMENTO DE SOUSA, 2016; ROSA, 2017; OLIVEIRA, 2014; SANTOS, 2017; RODRIGUES, 2017; ZANLORENZI, 2019; SILVA, 2019; GONÇALVES, 2013; PAIM, 2013; VERNI, 2016).

Como podemos verificar, os dados acima listados foram separados de acordo com os descritores que se inter-relacionam com a temática, além do descritor inicial PARFOR, após fazermos a primeira filtragem.

O primeiro descritor - "Pedagogia" - faz parte de 17 pesquisas das 22 analisadas. O curso de Pedagogia, entre os cursos ofertados pelo programa de formação de professores, é o mais procurado e o que mais possui quantidade de turmas ativas e concluídas no território nacional, desde o início de sua implantação em 2009, segundo dados da CAPES. A oferta do curso no âmbito do PARFOR tem como preocupação primeira atender a necessidade de formação inserida na Política Nacional de Formação de Profissionais do Magistério da Educação Básica, estabelecida pelo Decreto 6.755 de 29 de janeiro de 2009 e pela Portaria Normativa no 9 de 30/06/2009, que tem como propósito suprir o déficit de formação dos professores da educação básica no Brasil.

No âmbito das 17 pesquisas que tratam do descritor "Pedagogia", analisamos que as concepções de criança, de escola e de professor são muito importantes para a (re) significação da profissão docente, contudo, essas concepções estão marcadas num tempo, espaço e contexto (SANTOS, 2013), e são pouco exploradas. Inferimos que, no curso de Pedagogia, "o professor assume um papel de destaque, pois coloca-se sob ele e a sua formação a responsabilização para a melhoria da qualidade na educação básica (TEIXEIRA, 2018).

Observamos que o curso de Pedagogia cumpre com as especificidades elencadas no programa PARFOR, contribuindo, preponderantemente, para a certificação dos professores da educação básica que não possuem a formação em licenciatura. Destaca-se, segundo os estudos, o caráter intensivo da formação, associado às experiências e práticas docentes dos alunos, de maneira que garanta um dos seus princípios básicos: a articulação da teoria com a prática. 
Depreendemos (i) que as ações colaborativas com universidades públicas e comunitárias, em nível federal e estadual, "buscam dar conta da demanda na formação docente da educação básica, com destaque ao curso de Pedagogia, o qual tem como foco a docência na Educação Infantil e Ensino Fundamental Anos Iniciais" (AMORIM, 2013) e (ii) que apontam para implicações positivas da Pedagogia/PARFOR no âmbito da formação e da profissão de professores-estudantes, "na medida em que se está fortalecendo o processo de (re)constituição identitária desses profissionais, possibilitando suprir lacunas no interior da escola e/ou da sala de aula" (CARVALHO, 2014). De acordo com Pereira (2016), "o passo a passo da prática pedagógica exercida pelos alunos-professores segue uma rotina como na maioria das escolas: as exigências ao atendimento do currículo oficial, o planejamento de ensino e de aulas, os horários, as reuniões pedagógicas."

As pesquisas em geral apontam as características do PARFOR como importante política pública de formação de professores da Educação Infantil e Ensino Fundamental Anos Iniciais, sendo o curso de Pedagogia o que possui o maior número de turmas concluídas, segundo dados da CAPES (BRASIL, 2020). Entretanto, alguns estudos indicam os limites desse tipo de formação. O curso de Pedagogia no PARFOR é analisado como

\footnotetext{
um programa de caráter intensivo, com módulos de aulas em que cada disciplina é ministrada em uma semana, em alguns casos até mesmo em dias de feriados, o que, segundo a pesquisadora, tem se apresentado como uma experiência formativa bastante aligeirada, com duração curta e corrida (FREIRES, 2017, p. 110-111).
}

O segundo descritor - "Anos Iniciais" - foi pesquisado por apenas um pesquisador entre os 22 analisados. Como os descritores se inter-relacionam, o descritor em apreço, portanto, é objeto de estudo da Pedagogia e demais cursos oferecidos pelo PARFOR. No caso da pesquisa em análise, o propósito foi compreender o Ensino de Ciências Naturais em escolas públicas de uma região metropolitana brasileira, a partir das concepções e das práticas pedagógicas dos docentes em formação pelo PARFOR, que atuam nos anos Iniciais do Ensino Fundamental.

A "Educação Infantil" foi o terceiro descritor analisado nas pesquisas e despertou o interesse de três dos pesquisadores dos trabalhos analisados. Os pesquisadores analisaram: quais as (re)significações da profissão são elaboradas pelas professoras de Educação Infantil a partir do processo de formação em exercício; quais as contribuições do curso de Pedagogia PARFOR de um determinado instituto de educação para a melhoria das práticas pedagógicas de professores que atuam na Educação Infantil; qualidade da educação infantil no contexto do PARFOR; dentre outros elementos.

O quarto e último descritor filtrado/analisado - "Formação em Serviço ou Formação de Professores ou Formação Continuada" - foi verificado em todas as 22 pesquisas. Como um dos objetivos principais do PARFOR é propiciar a formação para os professores que estão atuando em sala de aula, mas não possuem formação em nível superior, isso explica a quantidade de pesquisas com o referido descritor. As pesquisas desses descritores, sendo relacionados ao PARFOR, tiveram objetivos variados e que se coadunam, a exemplo de: estudar a relação professor-aluno quando os alunos já são professores; compreender as re-existências epistemológicas e formativas de professores- 
estudantes aos atos de currículo constitutivos de um curso oferecido pelo programa; entre outros.

Assim, constatamos que, entre os descritores consultados no catálogo após a filtragem feita da primeira busca com o descritor PARFOR, os descritores "Pedagogia" e "Formação em Serviço ou Formação de Professores ou Formação Continuada" foram os que mais despertaram o interesse de pesquisa nos trabalhos analisados, o que caracteriza o PARFOR como um programa que tem mais ênfase no curso de Licenciatura em Pedagogia.

\section{POLITICAS PÚBLICAS E PARFOR}

Ainda que todas as pesquisas desta revisão de literatura estejam relacionadas ao PARFOR na condição de políticas públicas, nem todos os pesquisadores usam aportes teóricos conceituando aquilo que seriam políticas públicas. Aqueles que não conceituam referem-se ao conceito usando expressões do tipo: "políticas públicas educacionais", "políticas públicas educacionais para a formação de professores", "políticas públicas para a formação dos professores em exercício", "políticas públicas de formação continuada", "políticas públicas do sistema educacional", "políticas públicas de educação", "políticas públicas de formação docente", políticas públicas de formação inicial e continuada dos profissionais da educação", "políticas públicas de Estado", "políticas públicas educativas", entre outros.

Entre as 22 pesquisas selecionadas no mapeamento, apenas dois pesquisadores apresentaram o conceito de "Políticas Públicas". Cardoso (2018) utilizou o conceito de Souza (2006) ao afirmar que essas políticas são

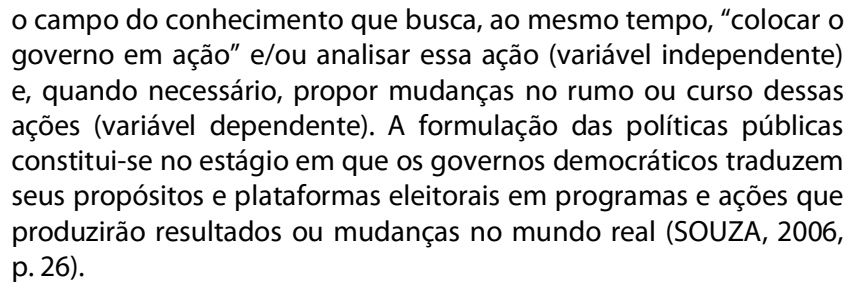
governo em ação" e/ou analisar essa ação (variável independente) e, quando necessário, propor mudanças no rumo ou curso dessas ações (variável dependente). A formulação das políticas públicas constitui-se no estágio em que os governos democráticos traduzem seus propósitos e plataformas eleitorais em programas e ações que produzirão resultados ou mudanças no mundo real (SOUZA, 2006, p. 26).

O outro pesquisador que apresentou um conceito de "Políticas Públicas" foi Sacramento de Sousa (2016), quando pontua que "é uma condição exclusiva do governo no que se refere à formulação, deliberação, implementação e monitoramento" de acordo com Azevedo (2003, p. 70).

O PARFOR, como um programa de políticas públicas, foi lançado em 2009 com a meta de formar professores que exercem a profissão sem formação exigida pela Lei de Diretrizes e Bases - LDB - (BRASIL, 1996). Disso, as primeiras pesquisas, em nível de mestrado e doutorado sobre o tema, passaram a ser armazenadas no Catálogo de Teses e Dissertações da CAPES em 2012. O PARFOR contribui para o alcance da Meta 15 do Plano Nacional de Educação (PNE). Essa meta aborda as estratégias que preveem implementar cursos e programas especiais para assegurar formação superior aos 
professores que estão em exercício e possuem somente formação de nível médio ou não possuem a formação específica à área de ensino na qual estão atuando (BRASIL, 2014).

O PARFOR (BRASIL, 2009) é destinado aos professores da rede pública da educação básica, em exercício há pelo menos 3 anos, sem formação adequada à LDB. Eles devem se inscrever nos cursos correspondentes às disciplinas em que atuam como professores na rede pública.

No contexto deste estudo, a importância de se pesquisar o PARFOR reside no fato de que "as políticas públicas educacionais efetivadas têm sido foco de debates, investigações, regulamentações e normatizações em âmbito nacional (SANTANA, 2016). Diante desse cenário, a formação de professores torna-se fundamental para o aperfeiçoamento da qualidade do ensino. Pensar a educação presume reflexão sobre a formação de professores e a prática pedagógica com qualidade. Para isso, faz-se necessário compreender a formação de professores para o desenvolvimento profissional docente, o que requer qualificação, valorização profissional e políticas adequadas, a exemplo do PARFOR, levando em consideração a importância do local de trabalho do professor.

Entendemos que analisar uma política pública é uma maneira de construir novas aprendizagens, levando em consideração que essas aprendizagens possam contribuir com a transformação da política e com seu aperfeiçoamento: marcos legais e conceituais da política, o que efetivamente foi materializado, executado.

A partir das leituras das pesquisas mapeadas, distinguimos as políticas públicas do PARFOR como importantes para a qualificação dos professores que estão em exercício, sendo que, em alguns contextos, há professores que residem em cidades/localidades que não lhes permitem o deslocamento para uma IES onde possam fazer um curso superior. Nesse aspecto, o PARFOR é relevante porque consegue chegar a esses docentes através de pequenos polos. Nesse sentido, os professores reconhecem que, mesmo com algumas dificuldades, o PARFOR como formação inicial em serviço tem valor, pois não oferece apenas cursos de graduação, mas aproxima os espaços de formação "ao diminuir as distâncias geográficas, garantindo o acesso e a possível permanência dos profissionais da educação que trabalham na Educação Básica sem habilitação na área em que atua" (SOUZA, 2015, p. 109).

No âmbito das pesquisas analisadas, inferimos que a política pública do PARFOR se anuncia, portanto, como uma probabilidade de ampliar a certificação de professores no cenário nacional e que, sem essa política, muitos professores ainda estariam em exercício apenas com a formação do antigo magistério. Percebemos também que há um vínculo entre o contexto da sala de aula e as teorias aprendidas no PARFOR, visto que as teorias possibilitam reflexões a respeito de suas práticas, fazendo com que os cursistas se sintam mais qualificados para desenvolverem a docência e conscientes de que o tempo dedicado ao curso favorece a prática pedagógica e corrobora a produção científica.

\section{CONSIDERAÇÕES FINAIS}

Com a finalidade de colaborar com o avanço de ações e políticas voltadas para a formação em serviço de professores da educação básica, foi realizado esta pesquisa. Os estudos relacionados a este levantamento bibliográfico apontaram que o PARFOR, 
enquanto temática central desta pesquisa, vem sendo analisado por pesquisadores da grande área de concentração em educação como parte das políticas públicas de formação de professores no país, assim como por outras áreas/programas de pósgraduação, como "Família na Sociedade Contemporânea", "Língua e Cultura" etc. Percebemos que as maiores concentrações das pesquisas ocorreram no contexto do curso de Pedagogia oferecido no âmbito do PARFOR em universidades públicas estaduais e federais em parcerias com estados e municípios, entretanto, o curso também é oferecido por Instituições Comunitárias de Educação Superior - ICES em muitos estados da federação.

Com relação aos objetivos propostos para este levantamento bibliográfico, identificamos que as características do PARFOR, nas 22 teses e dissertações acerca da educação infantil e dos anos iniciais do ensino fundamental, mantêm relações de intertextualidade com as categorias identificadas: Políticas Públicas e PARFOR, Formação em Serviço ou Formação Continuada ou Formação de Professores, assim como Profissionalização Docente, Desenvolvimento Profissional, Reflexão e Identidade Docente. Neste trabalho, enfatizamos as Políticas Públicas e o PARFOR. Vale ressaltar que, entre essas categorias, as mais recorrentes nos 22 trabalhos são: a Formação em Serviço, a Formação Continuada e a Formação de Professores. além disso, todos os conceitos indicados nas teses e dissertações sobre o PARFOR colaboram com o avanço de ações e políticas voltadas para a formação em serviço de professores da educação básica.

Os estudos destacam a preocupação com as experiências docentes procurando colaborar significativamente com as práticas pedagógicas dos professores em exercício. Assim, analisamos que é necessário maior investimento na formação reflexiva para corrigir possíveis lacunas, aprofundar os conhecimentos e potencializar os efeitos junto aos estudantes egressos do PARFOR para tornar suas práticas mais exitosas. Para isso, faz-se necessário ouvir e/ou ler narrativas dos alunos relacionadas ao curso, de forma que possamos compreender seus contextos de ensino, desafios e limitações. Essa é uma janela para novos estudos e nos encoraja a prosseguir na investigação junto aos professores e suas histórias de formação e desenvolvimento profissional docente.

Artigo recebido em: $14 / 08 / 2020$

Aprovado para publicação em: 03/11/2020

\section{CHARACTERISTICS OF PARFOR: A REVIEW OF BRAZILIAN DISSERTATIONS AND THESES}

ABSTRACT: Based on a survey carried out in the Catalog of Theses and Dissertations of the Brazilian institution for educational professionals development called "Coordenação de Aperfeiçoamento de Pessoal de Nível Superior-(CAPES)" in order to analyze the characteristics of the National Teacher Education Program called: "Plano Nacional de Formação de Professores da Educação Básica (PARFOR)". We seek to collaborate with the advancement of actions and policies focused on in-service education of basic school teachers. This is a bibliographic research using 
SANTOS, J. A. dos; ANUNCIATO, R. M. M.

Boolean operators with the descriptors PARFOR AND Pedagogy OR Early Years OR Early Childhood Education. The results confirm that PARFOR establishes relations with the identified categories, expanding the possibilities of teacher certification in the national scenario and contributes to the analysis of pedagogical practices. The implications for practices may constitute a field for future studies.

KEYWORDS: PARFOR. Public Policy. Teacher Training. Pedagogy.

\section{CARACTERÍSTICAS DE PARFOR: UNA REVISIÓN DE DISERTACIONES BRASILEÑAS Y ESTAS}

RESUMEN: A partir de una encuesta realizada en el Catálogo de Tesis y Disertaciones de la Coordinación para el Perfeccionamiento del Personal de Educación Superior (CAPES) con el fin de analizar las características del Programa Nacional de Formación Docente (PARFOR), buscamos colaborar con el avance de acciones y políticas centrado en la formación en servicio de los profesores de educación básica. Se trata de una búsqueda bibliográfica utilizando operadores booleanos con los descriptores PARFOR AND Pedagogy OR Early Years OR Early Childhood Education. Los resultados alcanzados confirman que PARFOR establece relaciones con las categorías identificadas, ampliando las posibilidades de certificación docente en el escenario nacional y contribuye al análisis de las prácticas pedagógicas. Las implicaciones para las prácticas pueden constituir un campo para estudios futuros.

PALABRAS CLAVE: PARFOR. Políticas Públicas. Formación de Profesores. Pedagogía.

\section{REFERÊNCIAS}

AMORIM, I. B. de. Entre casulo e asa: diálogos e movimentos dos selves de professorasestudantes no contexto da formação no PARFOR. 2013. 210f. Tese (Doutorado em Família na Sociedade Contemporânea) - Universidade Católica do Salvador, Salvador, 2013.

AZEVEDO, S. de. Políticas públicas: discutindo modelos e alguns problemas de implementação. In: SANTOS J.; ORLANDO A. dos. et al. Políticas públicas e gestão local: programa interdisciplinar de capacitação de conselheiros municipais. Rio de Janeiro, FASE, 2003.

BRASIL. Lei de Diretrizes e Bases da Educação Nacional. Lei número 9394, 20 de dezembro de 1996.

BRASIL. Decreto no 6.755, de 29 de janeiro de 2009. Institui a Política Nacional de Formação de Profissionais do Magistério da Educação Básica, disciplina a atuação da Coordenação de Aperfeiçoamento de Pessoal de Nível Superior - CAPES no fomento a programas de formação inicial e continuada, e dá outras providências. Diário Oficial da União, Brasília, DF, 30 jan. 2009.

Inter-Ação, Goiânia, v.46, n.1, p. 63-79, jan./mar. 2021. Disponível em: <http://dx.doi.org/10.5216/ia.v45i3.65002>. 
BRASIL. Lei n.13.005, de 25 de junho de 2014. Aprova o Plano Nacional de Educação PNE e dá outras providências. Diário Oficial da União, Brasília, DF. 26 jun 2014.

BRASIL. Ministério da Educação. Plano Nacional de Formação de Professores da Educação Básica - PARFOR. Coordenação de Aperfeiçoamento de Pessoal de Nível Superior. Brasília, 2020. Disponível em: http://www.capes.gov.br/educacaobasica/parfor. Acesso em: 7 ago. 2020.

CARDOSO, E. A. M. Os impactos do PARFOR na educação do campo como política de formação para a prática pedagógica dos egressos do curso de pedagogia da UESB, em Vitória da Conquista/ Ba. 2018. 227f. Dissertação (Mestrado em Educação) Universidade Estadual do Sudoeste da Bahia, Vitória da Conquista, 2018.

CARVALHO, C. P. As necessidades e expectativas das professoras estudantes da Pedagogia/Parfor sobre sua formação docente frente aos desafios da prática profissional. 2014. n.p. Dissertação (Mestrado em Educação) - Universidade Católica de Santos, Santos, 2014.

CUNHA, M. B. da. Para saber mais: fontes de informação em ciência e tecnologia. Brasília: Briquet de Lemos/Livros, 2001. 168p.

FREIRES, A. C. A formação em serviço no curso de Pedagogia da Universidade Federal do Pará: implicações na prática pedagógica do professor-aluno/egresso do PARFOR. 2017. 152f. Dissertação (Mestrado em Educação) - Universidade Federal do Pará, Belém, 2017.

GATTI, B. A. Análise das políticas públicas para formação continuada no Brasil, na última década. Rev. Bras. Educ., Rio de Janeiro, v. 13, n. 37, p. 57-70, abr. 2008.

GATTI, B. A. Formação inicial de professores para a educação básica: pesquisas e políticas educacionais. Estudos em Avaliação Educacional, São Paulo, v. 25, n. 57, p. 24 - 54, 2014.

GONÇALVES, A. L. Proação formando professores em atuação: entrecurrículo, experiência e metaformação como referências para uma hermenêutica no campo da formação. 2013. 137f. Tese (Doutorado em Educação) - Universidade Federal da Bahia, Salvador, 2013.

NORONHA, D. P.; FERREIRA, S. M. S. P. Revisões de literatura. In: CAMPELLO, B. S.; CONDÓN, B. V.; KREMER, J. M. (Orgs.) Fontes de informação para pesquisadores e profissionais. Belo Horizonte: UFMG, 2000. 
SANTOS, J. A. dos; ANUNCIATO, R. M. M.

OLIVEIRA, S. M. M. O Ensino de ciências naturais nos anos iniciais: concepções e práticas pedagógicas dos docentes em formação pelo PARFOR/Pedagogia/UFPA. 2014. 151f. Tese (Doutorado em Educação) - Universidade Federal do Pará, Belém, 2014.

PAIM, A. V. F. Atos de currículo e re-existências epistemológicas e formativas: um olhar crítico-hermenêutico sobre a formação de professores em atuação. 2013. 254f. Tese (Doutorado em Educação) - Universidade Federal da Bahia, Salvador, 2013.

PEIXOTO, J.P. Contribuições do curso de Pedagogia Parfor para as práticas pedagógicas de professores da Educação Infantil. 2015. 95f. Dissertação (Mestrado Profissional em Ensino de Ciências Exatas) - Universidade do Vale do Taquari, Lajeado, 2015.

PEREIRA, M. E. G. O curso de licenciatura em pedagogia/Parfor - Plano Nacional de Formação de Professores para a educação básica: implicações na prática pedagógica dos alunos-professores, do polo de Imperatriz MA. 2016. 127f. Dissertação (Mestrado em Educação) - Universidade Federal do Maranhão, São Luiz, 2016.

PIRES, J. M. Q. Da profissionalização à mudança das práticas pedagógicas: a contribuição do curso de Pedagogia/Parfor - Polo de Igarape-Miri. 2017. 142f. Dissertação (Mestrado em Educação) - Universidade Federal do Pará, Belém, 2017.

PORTELA, R. L. S. Os mistérios de Clarice: Narrativas de professoras egressas da primeira turma do curso de Licenciatura em Pedagogia da Parfor UFBA sobre a formação. 2019. 136f. Dissertação (Mestrado em Educação) - Universidade Federal da Bahia, Salvador, 2019.

RODRIGUES, D. F. Os significados atribuidos à formação e prática docente pelos egressos da $1^{\text {a }}$ turma de pedagogia do Parfor. 2017. 96f. Dissertação (Mestrado em Educação e Ensino) - Universidade Estadual do Ceará, Limoeiro do Norte, 2017.

ROSA, P. A. A perspectiva intercultural na formação de professores de língua estrangeira em serviço. 2017. 208f. Tese (Doutorado em Língua e Cultura) Universidade Federal da Bahia, Salvador, 2017.

SACRAMENTO DE SOUSA, N. Formação em exercício e desenvolvimento das práticas pedagógicas docentes: um estudo de caso no âmbito do Programa de Formação de Professores -PARFOR em Várzea do Poço-BA. 2016. 169f. Dissertação ( Mestrado em Educação e Diversidade) - Universidade do Estado da Bahia, Jacobina, 2016.

SALGADO, T. M. O. A formação de professoras-estudantes da Pedagogia/ PARFOR e o ensino de Música. 2013. 203f. Dissertação (Mestrado em Educação) - Universidade Católica de Santos, Santos, 2013. 
SANTANA, V. F. A formação do professor de matemática no contexto das políticas públicas: Uma breve análise do PARFOR. 2016. 98f. Dissertação (Mestrado em Educação para a Ciência) - Universidade Estadual Paulista "Júlio de Mesquita Filho", Bauru, 2016.

SANTOS, J. G. Narrativas de "professoras" da Educação Infantil: o processo de (re) significação da profissão a partir da formação em exercício. 2013. 189f. Dissertação (Mestrado em Educação) - Universidade Católica de Campinas, Campinas, 2013.

SANTOS, M. A. dos. Quando os alunos já são professores: ressentimento, teoria e prática na experiência do Parfor. 2017. 257f. Tese (Doutorado em Educação) Universidade Federal de São Carlos, São Carlos, 2017.

SILVA, H. E. F. da. Correndo terra... Furando mundos: as culturas na escrita de graduandos do PARFOR/Letras no Marajó. 2019. 263f. Tese (Doutorado em Letras) Universidade Federal do Pará, Belém, 2019.

SOUZA, C. Políticas Públicas: uma revisão de literatura. Sociologias, Porto Alegre, ano 8 , $n^{\circ} 16$, jul/dez, 2006, p. 20-45.

SOUZA, I. S. de. A formação inicial em serviço do professor/da professora de matemática: encontros e desencontros. 2015. 123f. Dissertação (Mestrado em Ciências e Matemática) - Universidade Federal de Sergipe, São Cristóvão, 2015.

SOUZA, R. R. Sistemas de recuperação de informações e mecanismos de busca na web: panorama atual e tendências. Perspect. ciênc. inf., Belo Horizonte, vol.11, n.2, p.161173, 2006.

TEIXEIRA, L. L. B. O plano nacional de formação de professores da educação básica (PARFOR): uma revisão da literatura (2013-2018). 2018. 110f. Dissertação (Mestrado em Educação) - Universidade Federal do Pará, Belém, 2018.

VERNI, D. E. S. Egressos do programa Parfor e profissionais das escolas em que atuam: olhares acerca da qualidade da educação infantil. 2016. 179f. Dissertação (Mestrado em Educação) - Universidade Católica de Santos, Santos, 2016.

ZANLORENZI, M. J. O PARFOR e a formação de professores para a Educação Básica: o caso do curso de Pedagogia da UEM. 2019. 187f. Tese (Doutorado em Educação) Universidade Estadual Paulista, Presidente Prudente, 2019.

JuCENILTON Alves dOS SANTOS: Atualmente, é coordenador técnico-pedagógico na Secretaria Municipal de Educação e Cultura de Itiruçu-BA. Doutorando em Educação pelo Programa de Pós-Graduação em Educação (PPGE) da Universidade Federal de São Carlos (UFSCar); Mestre em Letras pela Universidade Estadual do Sudoeste da Bahia - 
SANTOS, J. A. dos; ANUNCIATO, R. M. M.

UESB (2017); Membro do Corpo Editorial da Revista Eletrônica de Educação (REVEDUC) da UFSCar. Tem experiência na área de Ciências Humanas com ênfase em Antropologia Social (gênero, sexualidade) e Educação (Práticas Pedagógicas, Gestão Escolar e Formação de Professores), na área de Linguística e Letras com ênfase em Literatura Brasileira e Portuguesa, Leitura, Escrita e Gêneros Discursivos.

Orcid: https://orcid.org/0000-0003-1446-4079

E-mail: jucenilton@gmail.com

Rosa Maria Moraes Anunciato: Professora Titular do Departamento de Teorias e Práticas Pedagógicas da Universidade Federal de São Carlos (UFSCar). Bolsista Produtividade em Pesquisa nível 2. Possui mestrado em Educação pela Universidade Federal de São Carlos (1995) e doutorado em Educação pela Universidade Federal de São Carlos (2001). Coordena o grupo de pesquisa Estudos sobre a Docência: teorias e práticas. Tem experiência na área de Educação, com ênfase em Formação de Professores, atuando principalmente nos seguintes temas: formação de professores, concepções sobre a docência, anos iniciais do ensino fundamental, narrativas de professores e aprendizagem profissional da docência. De 2015 a 2018 foi coordenadora do Programa de PósGraduação em Educação da UFSCar - São Carlos- SP.

Orcid: http://orcid.org/0000-0003-1478-411X

E-mail: rosa@ufscar.br

Este periódico utiliza a licença Creative Commons Attribution 3.0, para periódicos de acesso aberto (Open Archives Iniciative - OAI). 